\title{
The relationship between psychological well-being and empathy quotient
}

\author{
Amirhesam Khajeh $^{\mathrm{a}^{*}}$, Ghafar Baharloo ${ }^{\mathrm{a}}$ and Fatemeh Soliemani ${ }^{\mathrm{b}}$
}

${ }^{a}$ M.A. in family counseling, Counseling Department, Esfahan University Branch, Esfahan, Iran ${ }^{b}$ M. A. in clinical psychology, Najafabad Branch, Islamic Azad University, Najafabad, Iran

\section{H R O N I C L E A B S T R A C T}

Article history:

Received December 28, 2013

Received in revised format April

152014

Accepted April 302014

Available online

May 22014

Keywords:

Psychological well-being

Empathy quotient

Autonomy

Environmental mastery

Personal growth

\begin{abstract}
This paper investigates the relationship between psychological well-being and empathy quotient among 200 married students, 100 female and 100 make, in city of Najafabad, Iran. The study uses a questionnaire with 84 questions for measuring psychological well-being, which consists of six parts including Autonomy, Environmental mastery, Personal growth, Positive relation with others, Purpose in life and Self-acceptance, each with 14 questions. Cronbach alphas for these six items were calculated as $0.83,0.86,0.85,0.88,0.88$ and 0.91 , respectively. In order to measure empathy quotient (EQ), the study uses EQ-short form, which consists of 22 questions. Cronbach alpha has been calculated as 0.93 , which is well above the minimum acceptable level of 0.70 . Using stepwise regression technique, the study determines a positive and meaningful relationship between EQ and psychological well-being.
\end{abstract}

\section{Introduction}

For years, there has been a question on what may cause happiness and well-being. For several years, there were several studies on relationship between the psychological well-being and empathy in different societies (Cheng \& Chan, 2005; Hogan, 1969; Ickes, 2003). According to Clarke et al. (2001), The Canadian Study of Health and Aging (CHSA) may provide an opportunity to study the positive characteristics of aging. CHSA-2 included the 18-item Ryff (Ryff \& Singer, 1998) multidimensional measure of well-being, which taps six core theoretical dimensions of positive psychological functioning. Their well-being measures in CSHA-2 provided an opportunity to study broad, descriptive patterns of well-being in Canadian seniors. Goldenfeld et al. (2005) analyzed some data from empathy quotient and systemizing quotient to examine whether these two items compete in brain or not and reported that they indeed react on each other. According to Krill et al. (2008), social exclusion, or ostracism, yields in a decrease in four fundamental human needs including belonging, control, self-esteem, and meaningful existence. Muncer and Ling (2006) performed a survey based on

\footnotetext{
*Corresponding author.

E-mail addresses: Amirhesam_khajeh@yahoo.com (A. Khajeh)
} 
confirmatory factor analyses comparing a unifactorial structure and a three correlated factor structure recommended that the three factors structure was a better fit. Exploratory analysis using modification indices indicated that it could be possible to measure the three factors of empathy; cognitive empathy, emotional reactivity and social skills with three five item scales. This paper presents an empirical investigation to study the effects of psychological well-being on empathy among some married people in Iran.

\section{The proposed study}

This paper investigates the relationship between psychological well-being and empathy quotient among 200 married students, 100 female and 100 make, in city of Najafabad, Iran. There are two hypotheses associated with the proposed study of this paper as follows,

1. There is a meaningful difference between psychological well-being and empathy.

2. There is a meaningful difference between female and male's psychological well-being and empathy.

The psychological well-being questionnaire was first developed by Ryff and Keyes (1995) with 120 questions and it was converted into some shorter forms of 84 and 18 questions. In this paper, we use the questionnaire with 84 questions, which consists of six parts including Autonomy, Environmental mastery, Personal growth, Positive relation with others, Purpose in life and Self-acceptance, each with 6 questions. Cronbach alphas for these six items were calculated as 0.83, 0.86, 0.85, 0.88, 0.88 and 0.91 , respectively. In order to measure empathy quotient (EQ), the study uses EQ-short form developed by Wakabayashi et al. (2006), which consists of 22 questions. Cronbach alpha has been calculated as 0.93 , which is well above the minimum acceptable level of 0.70 . Table 1 demonstrates some of basic statistics.

\section{Table 1}

The summary of mean and standard deviation

\begin{tabular}{lccc}
\hline Scale & Mean & Standard deviation & Number \\
\hline Psychological well-being & 302.8 & 42.30 & 200 \\
Empathy & 20.11 & 8.09 & 200 \\
\hline
\end{tabular}

We have performed Kolmogorov-Smirnov test to find out whether the data are normally distributed or not and the results have confirmed that all data are indeed follow normal distribution. Pearson correlation test between Psychological well-being and Empathy is equal to 0.53 with P-value $=0.000$. Therefore, there seems to be a positive and meaningful relationship between these two components.

\section{The results}

In this section, we present details of our findings on testing various sub-scale of Psychological wellbeing including Autonomy, Environmental mastery, Personal growth, Positive relation with others, Purpose in life and Self-acceptance. The implementation of this survey applies stepwise regression test where psychological well-being is the dependent variable and empathy is the independent variable. The results is as follows,

Empathy $=15.62+0.75$ Psychological well-being

Std. Dev. (4.05) (0.09)

$$
\mathrm{R}^{2}=0.22
$$

t-student $\quad 4.58 \quad 4.86$

Adjusted $\mathrm{R}^{2}=0.19$

Sig. Value $0.000 \quad 0.000$ 
Table 2 demonstrates the results of ANOVA test.

Table 2

The summary of ANOVA test

\begin{tabular}{lccccc}
\hline Model & Sum of Squares & df & Mean of Squares & F & Sig. \\
\hline Regression & 676.26 & 1 & 675.26 & 15.32 & 0.000 \\
Residual & 8221.45 & 198 & 125.21 & & \\
\hline Total & 8821.31 & 199 & & & \\
\hline
\end{tabular}

The results of Table 2 also confirm that there were linear relationship between the independent and dependent variable. We have also examined whether there is a meaningful relationship between Psychological well-being and empathy in terms of gender and Table 3 shows the results of our survey.

\section{Table 3}

The summary of testing the effect of gender on Psychological well-being and empathy

\begin{tabular}{lllccc}
\hline Variable & & Mean & df & t-value & Sig. \\
\hline Psychological well-being & Female & 344.13 & 198 & 0.04 & 0.85 \\
\cline { 2 - 3 } & Male & 344.96 & & & \\
\hline Psychological well-being & Female & 107.40 & 198 & 1.45 & 0.14 \\
Empathy & Male & 110.26 & & & \\
\hline
\end{tabular}

As we can observe from the results of Table 3, gender does not play essential role on relationship between psychological well-being and empathy when the level of significance is five percent.

\section{Conclusion}

In this paper, we have presented an empirical investigation to study the relationship between psychological well-being and empathy. The study has accomplished among 200 married people who lived in city of Najafabad, Iran. The results of the survey have confirmed that there psychological well-being could describe part of empathy and the results of this paper are consistent with findings of Stutzer and Frey (2006) and Depaulo (2004). However, the study did not find any evidence to believe gender had any impact on this relationship and this is consistent with Billington et al. (2007).

\section{Acknowledgement}

The authors would like to thank the anonymous referees for constructive comments on earlier version of this paper.

\section{References}

Billington, J., Baron-Cohen, S., \& Wheelwright, S. (2007). Cognitive style predicts entry into physical sciences and humanities: Questionnaire and performance tests of empathy and systemizing. Learning and Individual Differences, 17(3), 260-268.

Cheng, S. T., \& Chan, A. (2005). Measuring psychological well-being in the Chinese. Personality and Individual Differences, 38(6), 1307-1316.

Clarke, P. J., Marshall, V. W., Ryff, C. D., \& Wheaton, B. (2001). Measuring psychological wellbeing in the Canadian study of health and aging. International Psychogeriatrics, 13(S1), 79-90.

Depaulo, B. M. (2004). The scientific study of people who are single: an annotated bibliography. Academic advisory board of spectrum institute, research and policy division of the American association for single people (AASP), Glendale, CA, USA. 
Goldenfeld, N., Baron-Cohen, S., \& Wheelwright, S. (2005). Empathizing and systemizing in males, females and autism. Clinical Neuropsychiatry, 2(6), 338-345.

Hogan, R. (1969). Development of an empathy scale. Journal of consulting and clinical psychology, 33(3), 307-316.

Ickes, W. (2003). Everyday mind reading. New York: Prometheus Books.

Krill, A. L., Platek, S. M., \& Wathne, K. (2008). Feelings of control during social exclusion are partly accounted for by empathizing personality. Personality and individual differences, 45(7), 684-688.

Kohler, Hans-Peter, \& Joseph Lee Rodgers, \& Axel Skytthe. (2004). Subjective well-being, Fertility and partnerships: A bibliographic perspective. Paper presented at the 2005 Annual meeting of the Population Association of America, 31 march-2 April 2005, Philadelphia, PA.USA.

Muncer, S. J., \& Ling, J. (2006). Psychometric analysis of the empathy quotient (EQ) scale. Personality and Individual Differences, 40(6), 1111-1119.

Nettle, D. (2007). Empathizing and systemizing: What are they, and what do they contribute to our understanding of psychological sex differences?. British Journal of Psychology, 98(2), 237-255.

Ryff. C. D. \& Keyes, C. L. M. (1995). The structure of psychological well-being revisted. Journal of personality and social psychology, 69, 716-727.

Ryff. C. D. \& Singer, B. (1998). The contours of positive human health. Psychological Inquiry, 9, 128.

Stutzer, A., \& Frey, B. S. (2006). Does marriage make people happy, or do happy people get married?. The Journal of Socio-Economics, 35(2), 326-347.

Wakabayashi, A., Baron-Cohen, S., Wheelwright, S., Goldenfeld, N., Delaney, J., Fine, D., ... \& Weil, L. (2006). Development of short forms of the Empathy Quotient (EQ-Short) and the Systemizing Quotient (SQ-Short). Personality and individual differences, 41(5), 929-940. 